\title{
Differentiation of Eleven Fusarium spp. Isolated from Sugar Beet, Using Restriction Fragment Analysis of a Polymerase Chain Reaction- Amplified Translation Elongation Factor $1 \alpha$ Gene Fragment
}

\author{
Elke Nitschke, Maria Nihlgard, and Mark Varrelmann
}

First and third authors: Institute of Sugar Beet Research, Holtenser Landstr. 77, D-37079 Goettingen, Germany; second author: Syngenta Seeds AB, Box 302, 26123 Landskrona, Sweden. Accepted for publication 31 March 2009.

\begin{abstract}
Nitschke, E., Nihlgard, M., and Varrelmann, M. 2009. Differentiation of eleven Fusarium spp. isolated from sugar beet, applying restriction fragment analysis of polymerase chain reaction-amplified translation elongation factor $1 \alpha$ gene fragment. Phytopathology 99:921-929.

Sugar beet in Europe is commonly grown in wheat and maize crop rotations and subsequently pile-stored for several weeks. Beet is threatened by the colonization of saprophytic as well as pathogenic Fusarium spp. A tool for reliable identification based on sequence information of the translation elongation factor $1 \alpha$ (TEF-1 $\alpha)$ gene was developed for the numerous Fusarium spp. being isolated from sugar

obtained from sugar beet at different developmental stages from locations worldwide. Database sequences for additional species (F. sporotrichioides, F. poae, F. torulosum, F. hostae, F. sambucinum, F. subglutinans, and $F$. verticillioides), isolated from sugar beets in previous studies, were included in the analysis. Molecular sequence analysis of the partial TEF- $1 \alpha$ gene fragment revealed sufficient variability to differentiate between the Fusarium spp., resulting in species-dependent separation of the isolates analyzed. This interspecific divergence could be translated into a polymerase chain reaction restriction fragment length polymorphism assay using only two subsequent restriction digests for the differentiation of 17 of 18 species.
\end{abstract} beets. In all, 65 isolates from different species (Fusarium avenaceum, $F$. cerealis, F. culmorum, F. equiseti, F. graminearum, F. oxysporum, $F$. proliferatum, $F$. redolens, $F$. solani, $F$. tricinctum, and $F$. venenatum) were
Additional keywords: diagnosis, fungi, PCR-RFLP.
The genus Fusarium contains a variety of different taxa with various morphological characters. The soilborne plant-pathogenic Fusarium spp. are among the most economically important plant pathogens with regard to their persistence in soil, organic matter, or plant residues (10). Quantitative yield reduction (40) and fungal production of mycotoxins affecting food quality are of particular concern in Fusarium spp.-infected plants (58).

Sugar beet is attacked by various phytopathogenic and saprophytic fungi throughout the entire cultivation period and particularly during storage. Several early studies detected infections with a number of Fusarium spp. at different developmental stages of sugar beet $(1,8,27,35,36)$ and in harvested sugar beet during pile storage $(7,9)$. In addition to Fusarium oxysporum f. sp. betae, which induces phloem necrosis, chlorosis, wilting, and death of foliage (Fusarium yellows) as well as rot of taproots (cortex root rot) $(36,61)$, the isolated Fusarium spp. identified by their morphological characters included a broad spectrum of different species such as F. culmorum, F. equiseti, F. avenaceum, F. graminearum, $F$. acuminatum, $F$. solani, $F$. sporotrichioides, $F$. subglutinans, and $F$. moniliforme.

Infestations caused by $F$. oxysporum $\mathrm{f}$. sp. betae represent an increasing problem in the United States. At least eight states are affected by Fusarium yellows in sugar beet-producing areas, resulting in considerable yield reductions $(20,23,44,54)$. Recently, for Minnesota and Wyoming, Hanson (22) reported F. graminearum as an additional causal agent of Fusarium yellowing, formerly associated only with $F$. oxysporum f. sp. betae infec-

Corresponding author: M. Varrelmann; E-mail address: varrelmann@ifz-goettingen.de

doi:10.1094/PHYTO-99-8-0921

(c) 2009 The American Phytopathological Society tions. Possible implications of $F$. graminearum isolated from sugar beet on crops grown in the same rotation were pinpointed by investigations of Estrada et al. (16) and Burlakoti et al. (13), who demonstrated the cross-pathogenicity of $F$. graminearum isolates from sugar beet to cereals and potato. Furthermore, the general ability of mycotoxin production of these cross-pathogenic isolates was shown $(11,13)$.

In addition to Fusarium spp. infestations of sugar beet, Bosch and Mirocha (7) confirmed that several species produced mycotoxins resulting in zearalenon accumulation in sugar beet and fiber samples derived thereof. Because different Fusarium spp. possess variable toxigenic potential, accurate identification is necessary.

Traditionally, the identification of Fusarium spp. is based on morphology, including distinctive features such as the shape, size, and septation of conidia, chlamydospores; and the evaluation of additional characteristics of the general mycelium growth rate and mycelium color on agar cultures (31). In general, members of the genus Fusarium are commonly accepted to be difficult to identify at the species level relying only on microscopic traits.

In the last decade, molecular-based techniques have made a significant impact on the speed and reliability of fungal species identification for diagnostic as well as phylogenetics and taxonomic purposes $(32,46,47,49,50,56,60)$. Established DNA-based methods for Fusarium spp. detection and identification include species-specific polymerase chain reaction (PCR) assays $(6,25$, $26,30,52)$, as well as the use of conserved DNA regions for comparative sequencing and phylogenetic analysis $(18,49)$ and development of PCR-restriction fragment length polymorphism (RFLP) assays. The application of species-specific PCR is reliable in well characterized host-pathogen interactions but of limited use when multiple species need to be differentiated. Thus, a method that rapidly distinguishes several Fusarium spp. is 
needed. The sequence analysis of ribosomal RNA (rDNA) $(3,21,28,38), \beta$-tubulin (49), or translation elongation factor $1 \alpha$ (TEF-1 $\alpha)(28,29,49)$ allows a more reliable identification but is more time and labor intense. In particular, the TEF-1 $\alpha$ gene was shown to be a useful genetic region for phylogenetic and taxonomic studies in Fusarium spp. Therefore, the TEF-1 $\alpha$ has been used as a single-locus identification tool in the assembled FUSARIUM-ID v.1.0 database (18).

The development of PCR-RFLP assays offers further possibilities for simplified, fast, and routine determination and diagnosis, especially where time and expense may preclude sequencing efforts. Duggal et al. (14) observed polymorphisms between and within Fusarium spp. in the internal transcribed spacer (ITS) region. However, Turner et al. (59) demonstrated that sequence divergence in the ITS region was too small and insufficient for the resolution of closely related species such as $F$. tricinctum and $F$. avenaceum by PCR-RFLP analysis. Other areas showed promise; for example, the intergenic spacer of rDNA (IGS) allowed a clear differentiation, as demonstrated by Edel et al. (15). Therein, 18 different species could be discriminated by comparisons and classifications of haplotype formation by using a minimum of four different restriction enzyme digests. Further analyses were able to relate IGS-PCR-RFLP analysis to host specificity and mycotoxin-producing ability based on five to six subsequent restriction enzyme digests $(33,34)$. A number of IGSPCR-RFLP analyses predominantly have been used to charac- terize intraspecific relationships in $F$. culmorum (37), F. moniliforme (24), and $F$. oxysporum (39). Interestingly, the TEF-1 $\alpha$ gene fragment was only recently subjected to PCR-RFLP analysis for successful differentiation of the three $F$. oxysporum clades (6), thereby proving the potential to use TEF- $1 \alpha$ gene fragment variability for intraspecific discrimination in RFLP analyses.

No fast and reliable tool currently is available for the accurate identification of the numerous species frequently isolated from sugar beet. The objective of this study was the development of a simple diagnostic technique for the routine identification of Fusarium spp. frequently occurring in sugar beet fields. Of particular interest is the discrimination of common soil saprophytes and maize- and cereal-associated species due to the importance of stalk crops in sugar beet crop rotations. Based on the sequence information of the TEF- $1 \alpha$ gene, an RFLP assay of a single fungal-derived PCR product was developed, differentiating, in total, 18 Fusarium spp. assembled of 11 species isolated from sugar beet and 7 closely related species represented by their TEF$1 \alpha$ nucleotide sequences deposited in databases.

\section{MATERIALS AND METHODS}

Fusarium isolates and microscopic analysis. The Fusarium isolates analyzed in this study are listed in Table 1 with their geographic origin. The German isolates were collected, identified, and stored at the Department of Phytopathology, Institute of

TABLE 1. Fusarium isolates originating from sugar beet used in this study ${ }^{\mathrm{a}}$

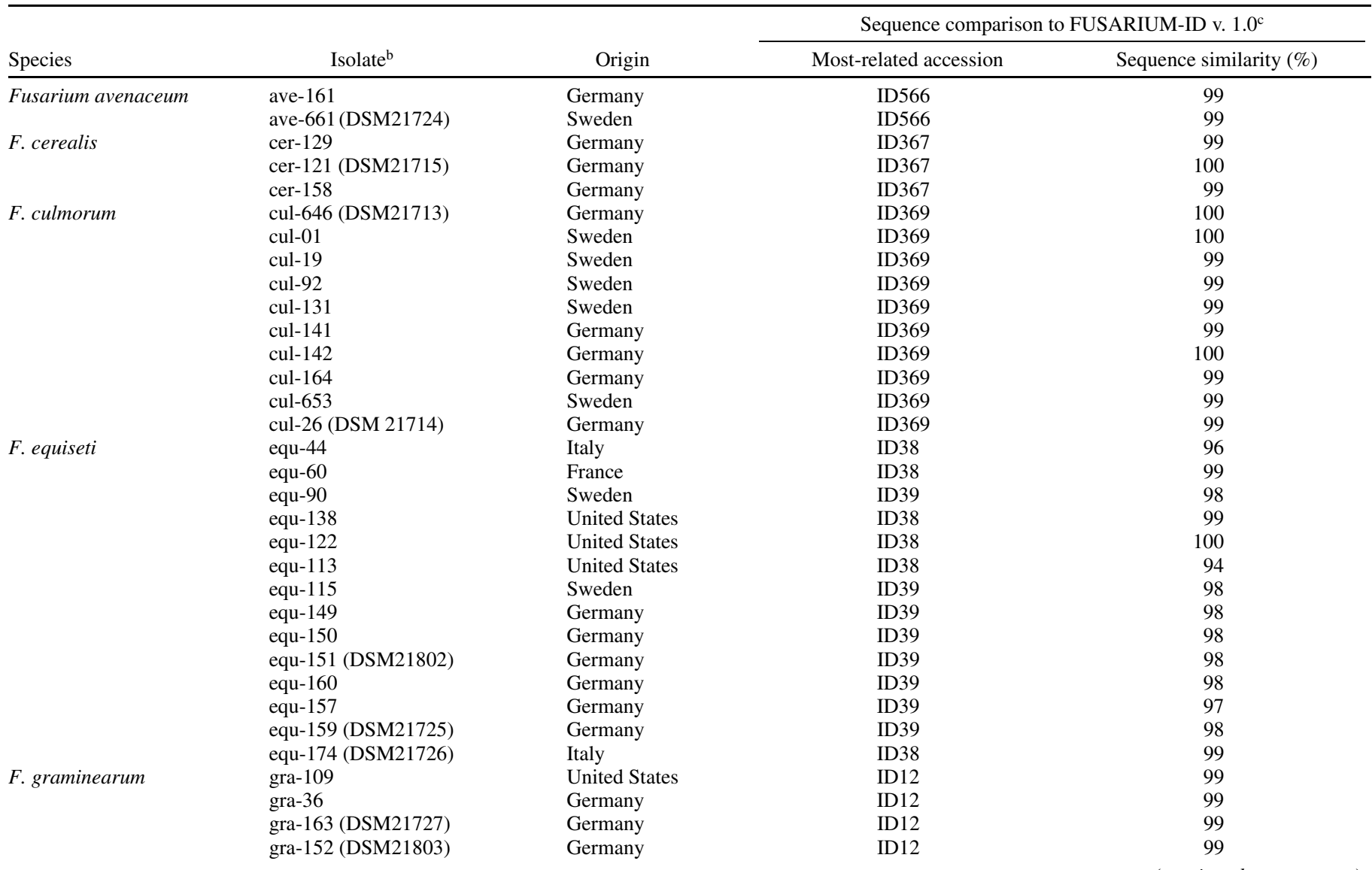

${ }^{a}$ Sugar beet-derived isolates of this study, their most related database accessions, and additional database accessions of related Fusarium spp. are subject of all translation elongation factor- $1 \alpha$ investigations.

${ }^{b}$ Representatives of each species were deposited in the open collection of the German collection of microorganisms and cell cultures as indicated by their DSM deposition number.

${ }^{c}$ Most related sequence from FUSARIUM-ID.

${ }^{\mathrm{d}}$ Sequences of related species (1) as well as representatives of the three clades of Fusarium solani (2) from FUSARIUM-ID.

e Sequences of related species from GenBank. 
Sugar Beet Research. The isolates derived from sugar beet outside Germany were collected by the Plant Pathology Unit at Syngenta Seeds, Landskrona, Sweden. To isolate Fusarium spp. from sugar beet tissue, the following isolation procedure was used. Throughout the growing season, freshly harvested sugar beet plants displaying root rot symptoms were washed thoroughly and a piece of beet tissue of 0.3 to $0.5 \mathrm{~cm}^{3}$ was removed from the center of the beet using a surface-sterilized knife. Following surface sterilization with $70 \%$ ethanol for $30 \mathrm{~s}$ and subsequent washing in sterile double-distilled water, tissue was placed on potato dextrose agar (PDA) supplemented with streptomycin (150 mg liter $\left.{ }^{-1}\right)$. All isolates are held as long-term cultures at the Department of Phytopathology. For microscopic and nucleic-acid-based analysis, monoconidial cultures of the isolates were established on small nutrient agar (SNA) (41). Microscopic characterization of conidia and conidiophores of the analyzed isolates was carried out according to the methods of Leslie and Summerell (30) to confirm the molecular data acquired. Additional isolates were obtained from two fungal collections, the Centraalbureau voor Schimmelcultures (CBS, The Netherlands) and the German collection of microorganisms and cell cultures (DSMZ, Germany) and included as references (Table 2).

Fungal DNA extraction and PCR amplification. Monoconidial isolates were grown on PDA at $22^{\circ} \mathrm{C}$ under white light for 10 days. DNA was extracted from mycelium using the DNeasy kit (Qiagen, Germany) according to the manufacturer's instructions. To amplify the TEF- $1 \alpha$ gene fragment with an approximate length of $700 \mathrm{bp}$, primers EF1 and EF2 (46) were used. A standard PCR reaction was carried out with 35 cycles of denaturing at $95^{\circ} \mathrm{C}$ for $45 \mathrm{~s}$, annealing at $50^{\circ} \mathrm{C}$ for $45 \mathrm{~s}$, and extension at $72^{\circ} \mathrm{C}$ for $1 \mathrm{~min}$. The amplification reaction was verified by electrophoresis on a $1 \%$ agarose gel containing ethidium bromide and visualized on a UV transilluminator.

Molecular cloning of PCR products and sequencing. The TEF-1 $\alpha$ PCR products were purified and cloned into the pGemTeasy vector (Promega, Germany) according to the manufacturer's instructions. Sequencing of clones in both directions was carried out commercially (MWG Biotech, Germany) using standard primers flanking the multiple cloning site of the cloning vector.

Sequence analysis. Sequences were edited using VectorNTI (Invitrogen, Germany). Sequence alignment of the TEF-1 $\alpha$ PCR product sequence excluding the primer sequences and generation of dendrograms was carried out by ClustalX (57). The sequence alignment included a total of 65 isolates representing 11 species (Table 1). To expand the available dataset and test the reliability of the phylogenetic analyses and PCR-RFLP patterns, database accessions of Fusarium isolates were integrated into the investigations as listed in Table 1. FUSARIUM-ID-derived sequences were labeled by their ID in combination with an abbreviation for the species (e.g., hos-ID48 for $F$. hostae, database entry ID48). TEF-1 $\alpha$ sequences of $F$. subglutinans (sub-ID77), $F$.

TABLE 1. (continued from preceding page)

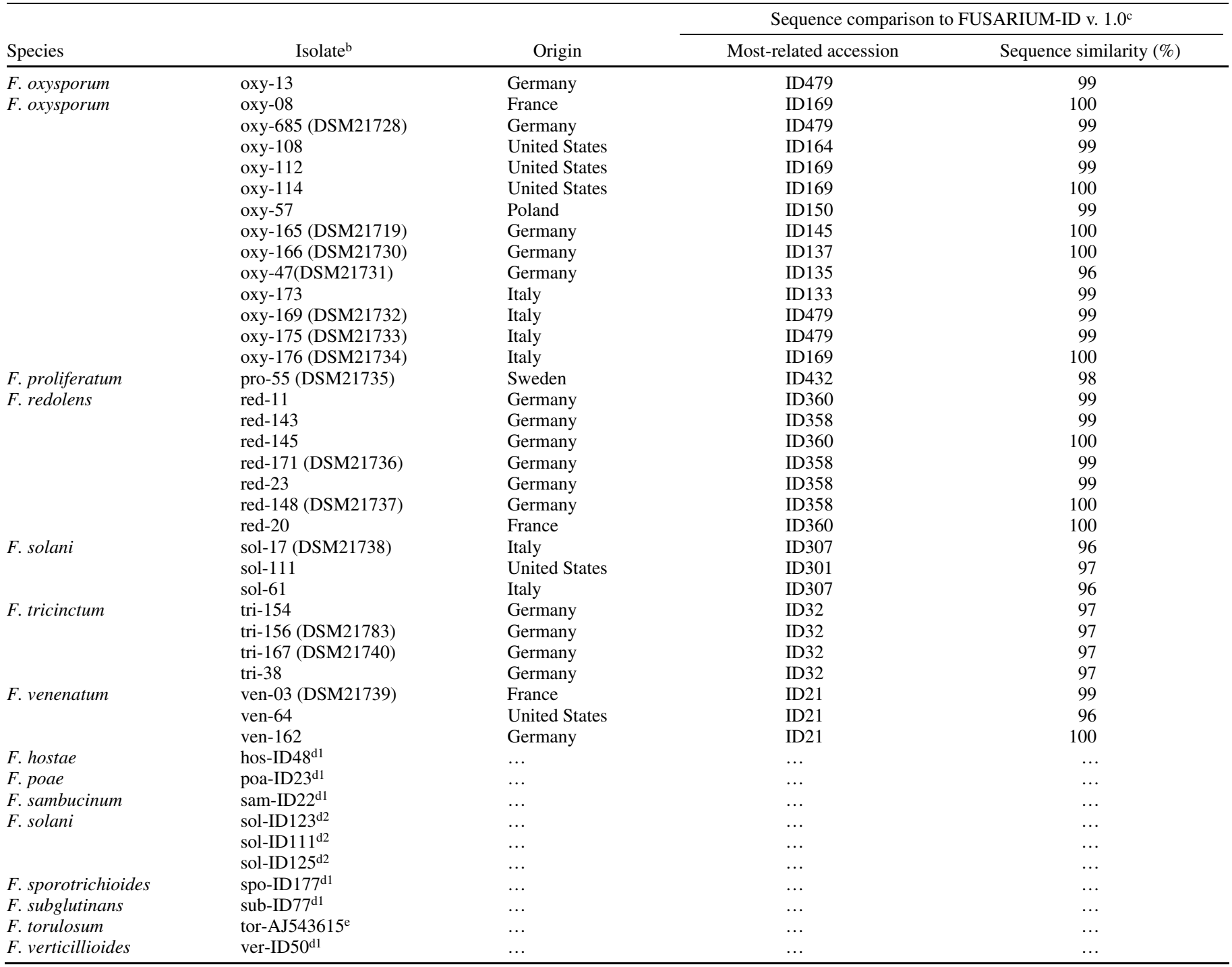


sporotrichioides (spo-ID177), F. poae (poa-ID23), and F. verticillioides (ver-ID50) were supplemented based on the isolated Fusarium spp. spectrum of Bosch and Mirocha (7). Moreover, due to common strong morphological similarities, database TEF$1 \alpha$ sequences of Fusarium spp. potentially to be confused with species isolated from sugar beet were included. These were, notably, $F$. hostae (hos-ID48), due to its close relationship with $F$. redolens $(5,19)$, as well as $F$. sambucinum (sam-ID22) and $F$. torulosum (GenBank accession no. AJ543616), due to their relationship with $F$. venenatum $(42,43)$. Additionally, TEF-1 $\alpha$ sequences were supplemented to represent the three clades of $F$. solani (45). Differentiation of $F$. oxysporum clades (49) was according to Bogale et al. (6). Dendrograms were visualized using TreeView (51), showing the phylogenetic relationships between the nucleotide sequences. In order to evaluate the support for the observed branching topologies for maximum parsimony, bootstrap analysis was performed and values were calculated from 1,000 replicates, indicated at each node. All the newly obtained sequences have been submitted to the EMBL/GenBank sequence database (FY939658 to FY939722).

RFLP analysis of PCR products. Unpurified TEF- $1 \alpha$ PCR product $(20 \mu \mathrm{l})$ was digested with 5 units of different restriction enzymes, including BstUI, BspHI, XhoI, MaeII, and AluI (Fermentas, Germany), using the buffers supplied by the manufacturer in a total volume of $25 \mu \mathrm{l}$ at $37^{\circ} \mathrm{C}$ overnight to ensure complete digestion. Restriction fragments were resolved by electrophoresis on 3\% agarose gels and visualized using a UV transilluminator as described above. Determination of restriction patterns were made by comparison to a parallel-resolved DNA marker (50 bp ladder; Fermentas). In silico analyses of digestion patterns of TEF- $1 \alpha$ gene fragments for different restriction enzymes were performed using VectorNTI.

\section{RESULTS}

Isolation and morphological analysis. Analysis of fungal species from sugar beet collected in Germany and worldwide displaying root rot symptoms resulted in a subset of 65 isolates. In all, 34 isolates from Germany, 22 from different European countries, and 9 from the United States were identified as $F u$ sarium spp. Identification to the species level was achieved by detailed microscopic analysis of typical Fusarium structures and enabled a grouping of the isolates into 11 different Fusarium spp.

TABLE 2. Overview on reference Fusarium isolates of culture collections used for proof and verification of polymerase chain reaction restriction fragment length polymorphism analyses

\begin{tabular}{|c|c|c|}
\hline Species & $\begin{array}{l}\text { Accession of } \\
\text { reference isolate }\end{array}$ & Host \\
\hline Fusarium avenaceum & DSM62161 & Dianthus caryophyllus \\
\hline \multirow[t]{2}{*}{ F. cerealis } & CBS134.80 & Zea mays \\
\hline & CBS 135.80 & Beta vulgaris \\
\hline \multirow{3}{*}{ F. culmorum } & DSM62191 & Triticum aestivum \\
\hline & DSM6223 & Corylus avellana \\
\hline & CBS250.52 & Secale cereale \\
\hline F. equiseti & DSM62202 & C. avellana \\
\hline F. graminearum & CBS389.62 & T. aestivum \\
\hline F. poae & DSM62376 & Avena sativa \\
\hline F. proliferatum & DSM62267 & Z. mays \\
\hline \multirow[t]{2}{*}{ F. redolens } & DSM62379 & Dianthus caryophyllus \\
\hline & DSM62380 & Asparagus officinalis \\
\hline F. sambucinum & DSM62433 & Beta vulgaris \\
\hline F. sporotrichioides & DSM62376 & Avena sativa \\
\hline F. tricinctum & CBS144.78 & T. aestivum \\
\hline F. verticillioides & DSM62267 & Z. mays \\
\hline
\end{tabular}

${ }^{a}$ DSM-labeled isolates were provided by the German collection of microorganisms and cell cultures and CBS-labeled cultures were retrieved from the culture collection of The Centraalbureau voor Schimmelcultures, The Netherlands. representing a broad spectrum of common soilborne pathogenic and saprophytically living species (Table 1).

Phylogenetical analysis of Fusarium isolates. To test whether the TEF-1 $\alpha$ gene would be feasible for differential detection and subsequent molecular identification, initially, DNA samples from all isolates were used for PCR amplification of an $\approx 700$-bp TEF$1 \alpha$ gene fragment. No amplification products were obtained using DNA samples from other common soilborne and sugar-beetcolonizing fungi (Pythium ultimum, Aphanomyces cochlioides, Phoma betae, and Rhizoctonia solani), proving the Fusarium specificity of the EF1/EF2 primer pair (data not shown). The TEF-1 $\alpha$ PCR products were T-vector cloned and subsequently sequenced. The TEF-1 $\alpha$ fragment sequences, including primer sequences, were subjected to a Fusarium database (FUSARIUMID v. 1.0) comparison using the BLAST-N search utility (2). The most closely related sequences, as well as their percentage of sequence homology to the TEF-1 $\alpha$ sequence of each isolate resulting from this search, are displayed in Table 1. In all cases, the results of TEF- $1 \alpha$ sequence comparison to the FUSARIUMID database confirmed the preliminary identification based on the microscopic analysis. The high degree of nucleotide sequence similarity (94 to 100\%) for all analyzed isolates indicated that the intraspecific divergence was limited for the 11 different species despite the worldwide geographical origin of the isolates included. Overall, out of the Fusarium spp. isolated from sugar beet and supplementary species represented by database sequences, 18 different species were included in the TEF-1 $\alpha$ gene fragment sequence comparison (Table 1). ClustalX multiple sequence comparisons of the TEF- $1 \alpha$ gene fragments of all isolates in this study revealed stretches of high similarity next to stretches of high divergence (data not shown). The resulting dendrogram (Fig. 1A) showed that the analyzed TEF- $1 \alpha$ gene region possessed sufficient variability to differentiate between the 18 investigated Fusarium spp., resulting in a clear, well-structured, and speciesdependent separation of the analyzed isolates forming nine main branches. The main dendrogram revealed a good overall resolution of all analyzed species resulting either in branches containing only isolates from one species (branch 4, 6, 8, and 9) or branches grouping between two and four species. Known related species clustered using this method; for example, the branch of $F$. redolens and $F$. hostae (branch 1 ) was separated from the cluster formed by $F$. oxysporum, $F$. proliferatum, $F$. subglutinans, and $F$. verticillioides (branch 2); the group of $F$. culmorum, $F$. cerealis, and $F$. graminearum (branch 5); or the branch containing $F$. sambucinum and $F$. venenatum (branch 7 ) as well as $F$. avenaceum, F. tricinctum, and F. torulosum (branch 3). The overall alignment did not clearly resolve TEF- $1 \alpha$ sequence divergence of isolates belonging to one single or more closely related species. Therefore, sequences of individual branches (supported by bootstrap values of $>900$ ) were each used for a separate ClustalX multiple sequence comparison. These analyses resulted in a clear species-specific resolution for each subbranch (Fig. 1B to G). Every isolate-derived sequence in this study clustered with sequences of the predicted species, revealing enough polymorphism to distinguish and identify even isolates of closely related species. Branch 1 was built up by the isolates of $F$. redolens and $F$. hostae, wherein the isolate of $F$. hostae clearly outgrouped from the isolates of $F$. redolens (Fig. 1B). Similarly branch 3,5 , and 7 showed a species-specific separation of $F$. torulosum, F. tricinctum, and F. avenaceum (Fig. 1D); F. cerealis, $F$. culmorum and, F. graminearum (Fig. $1 \mathrm{E}$ ); as well as $F$. venenatum and $F$. sambucinum (Fig. $1 \mathrm{~F}$ ), respectively. In branch 7 , the U.S. isolate ven-64 of $F$. venenatum separated noticeably from the German $F$. venenatum isolates by its TEF- $1 \alpha$ nucleotide composition as indicated by the scale bar (Fig. 1F). Branch 2 consisted of the species $F$. oxysporum, $F$. verticillioides, $F$. subglutinans, and $F$. proliferatum. F. verticillioides, $F$. subglutinans, and $F$. proliferatum were distinguishable and well separated from 
A
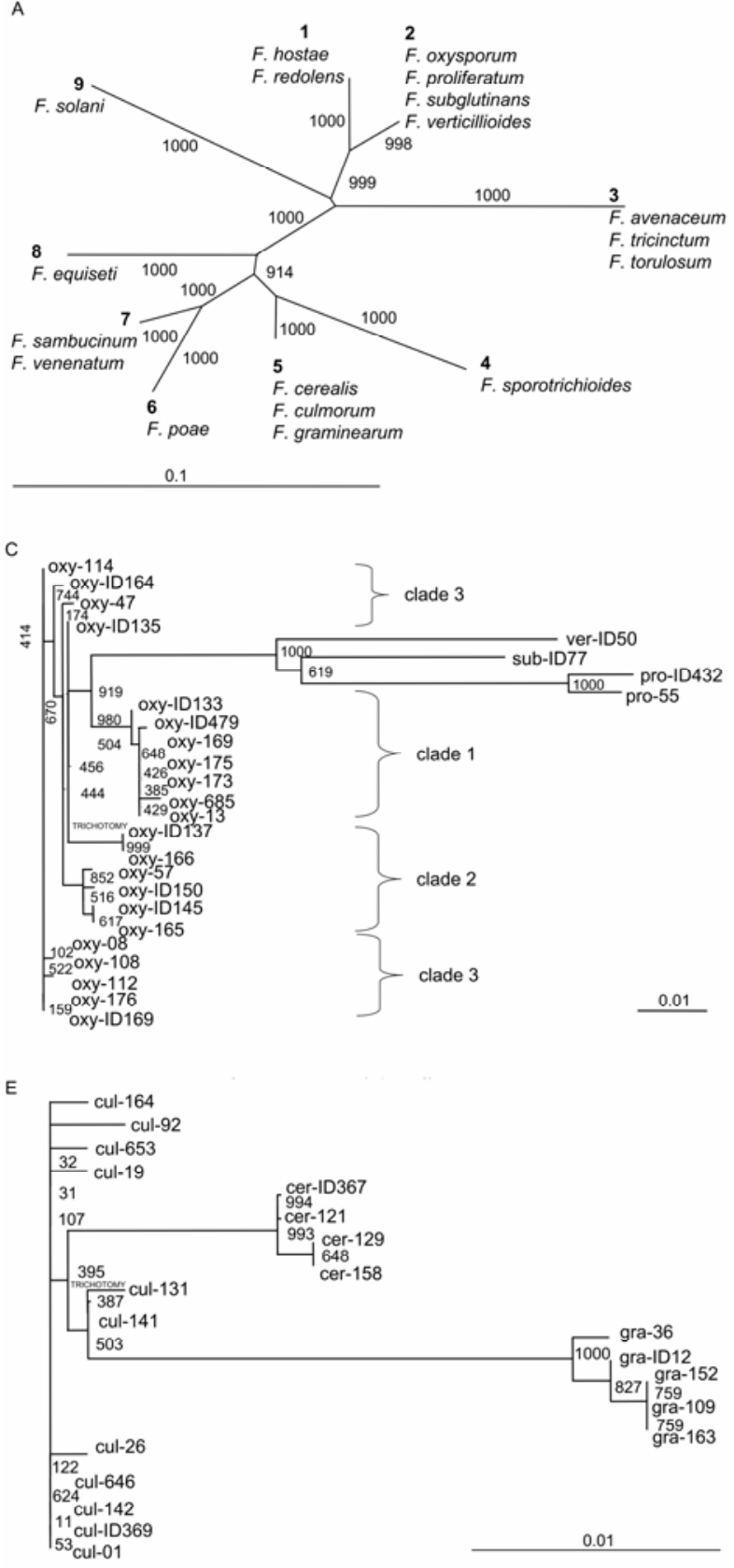
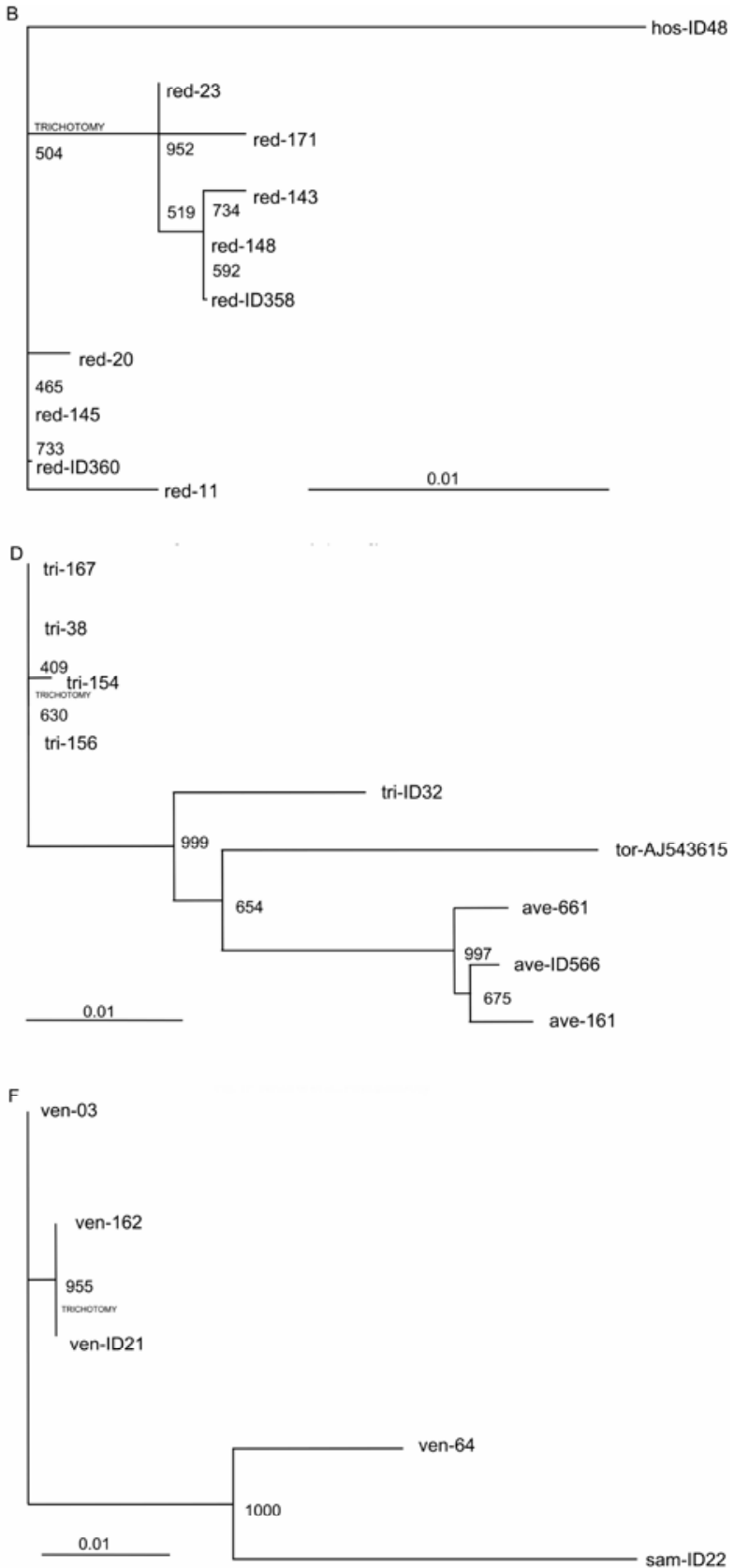

G

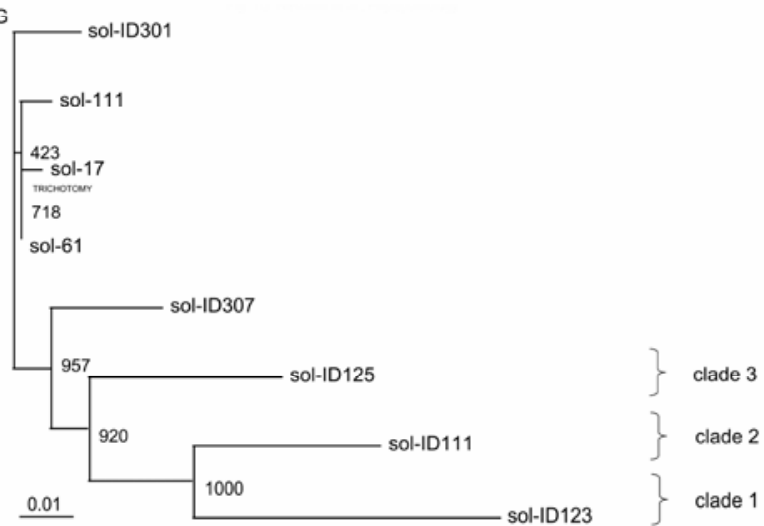

Fig. 1. A, Unrooted tree showing the phylogenetic relationships between translation elongation factor $1 \alpha$ (TEF-1 $\alpha$ ) sequences of all Fusarium isolates of this study plus Fusarium database sequences displayed in Table 1. Clusters of Fusarium isolates at the end of each main branch (1 to 9) forming main groups of closely related Fusarium spp. or isolates of one species were removed because of the low resolution of this view. B to G, Rooted phylogenetic trees of TEF-1 $\alpha$ sequences clustering into main branches 1 to 9 in A. Sequences were aligned and neighbor-joining trees constructed using ClustalX. Boot strap values were calculated from 1,000 replicates and are indicated at each node. The scale bar indicates 0.1 and $0.01 \%$ substitution per nucleotide, respectively. 
the isolates of $F$. oxysporum (Fig. 1C). The latter species differentiated into several subbranches which could be assigned to the three clades of F. oxysporum defined by O'Donnell (49) (Fig. 1C, parenthesis). However, investigations of pathogenicity still need to be performed to differentiate these sugar-beet-derived isolates into pathogenic and nonpathogenic ones because this question was not addressed using the TEF- $1 \alpha$ sequence analysis. TEF-1 $\alpha$ sequences representing isolates of sugar-beet-pathogenic F. oxysporum f. sp. betae were not available from the FUSARIUMID or GenBank database, preventing the disclose of any further information concerning the $F$. oxysporum intraspecific relationship of the sugar-beet-derived $F$. oxysporum isolates of this study out of the analyzed TEF- $1 \alpha$ gene region. Phylogenetic relationships of sugar-beet-derived $F$. solani isolates (branch 9) were analyzed in detail due to the inclusion of representative sequences for the three clades of $F$. solani (Fig. 1G). However, the sugarbeet-derived sequences clearly outgrouped and obviously were not related to these clades.

Development of a TEF- $1 \alpha$ gene-fragment-based PCR-RFLP assay for differentiation of Fusarium spp. Based on the reliable species-specific discrimination of the TEF- $1 \alpha$ gene fragment, the sequences were used for the development of a PCR-RFLP assay to simplify Fusarium spp. determination. Initially, TEF- $1 \alpha$ sequences of all sugar-beet-derived Fusarium isolates, including all the database references as listed in Table 1, were subjected to in silico RFLP analyses. Testing of several frequent cutting restriction enzymes revealed the suitability of $B s t \mathrm{UI}$ to provide characteristic band patterns to differentiate between groups of closely related species (Table 3). The formation of these groups corresponded to the clustering of the main dendrogram in Figure 1A. The species $F$. poae, $F$. solani, and $F$. graminearum were characterized by a species-specific BstUI-related haplotype and thereby distinguishable from all other analyzed species by this single restriction digest (Table 3). However, as expected, in most cases, closely related species gave identical restriction patterns. This overlapping was seen within groups formed in the main dendrogram (Fig. 1A) (e.g., branch 1, formed by F. hostae and F. redolens, or branch 3 , consisting of $F$. torulosum, $F$. avenaceum, and $F$. tricinctum). Few species clustering into different branches also produced identical or very similar Bst UI haplotypes (e.g., branch 4 and 7 [F. sporotrichioides, $F$. venenatum, and $F$. sambucinum] or branch 2- and 8-derived isolates of $F$. oxysporum and F. equiseti) (Table 3). Whereas, for most species, a single Bst UIrelated restriction pattern was conserved in all tested isolates. Multiple restriction patterns were generated from the isolates of $F$. oxysporum and $F$. equiseti (Table 3 ). There was no correlation between the BstUI-related haplotype formation of $F$. oxysporum isolates and the clustering into different clades. Although, for analyzed $F$. oxysporum sequences, Bst UI fragmentation was consistent and reproducible for sugar-beet-derived as well as database-derived sequences, the $F$. solani-related Bst $\mathrm{UI}$ fragmentation pattern was only valid and specific for sugar-beet-derived sequences and their closest related database sequences. In silico analyses of database sequences for $F$. solani isolates belonging to different formae speciales, mating type, or clade were characterized by highly divergent BstUI patterns (data not shown). However, despite different geographical origins, the sugar-beetderived $F$. solani sequences exhibited a specific $B s t \mathrm{UI}$ restriction pattern different from all other analyzed Fusarium spp.

TEF-1 $\alpha$ PCR products from the 11 different sugar-beet-derived Fusarium spp. were subsequently Bst UI digested and a clearly resolved fragmentation of sizes as small as $40 \mathrm{bp}$ was achieved by electrophoresis on 3\% agarose gels (Fig. 2). In addition, reference isolates of different Fusarium spp., which originated from several diverse hosts, were included in this analysis (Table 2). Generally, the single BstUI-digested TEF-1 $\alpha$ PCR fragments resulted in clearly distinguishable restriction patterns enabling separation of cereal-associated species such as $F$. culmorum, $F$. cerealis, $F$. graminearum, and $F$. tricinctum from species such as $F$. equiseti, as well as a differentiation of $F$. redolens from the wilting pathogen $F$. oxysporum (Fig. 2). The final species determination depended on a second restriction digest according to the pregrouping results of $B s t \mathrm{UI}$ digestion. The combination of $B s t \mathrm{UI} / B s p \mathrm{HI}$, $B s t \mathrm{UI} / X h o \mathrm{I}, B s t \mathrm{UI} / B s r \mathrm{BI}, B s t \mathrm{UI} / M a e \mathrm{II}$, and Bst $\mathrm{UI} / A l u \mathrm{I}$ in silico restriction digests resolved $F$. cerealis/F. culmorum, $F$. torulosum $/ F$. avenaceum $/ F$. tricinctum, $F$. redolens $/ F$. hostae, $F$. sporotrichioides $/ F$. sambucinum $/ F$. venenatum, and $F$. equiseti $F$. subglutinans/F. verticillioides/F. oxysporum, respectively (Table 3 ). This possibility of species-specific differentiation was proven for 10 of the 11 different sugar-beet-derived Fusarium spp. (Figs. 2

TABLE 3. Analysis of translation elongation factor- $1 \alpha$ gene fragment sequence of 18 Fusarium spp. enabling species-specific differentiation by in silico polymerase chain reaction restriction fragment length polymorphism analysis using two subsequent different restriction digests

\begin{tabular}{|c|c|c|c|c|c|c|}
\hline Branch $^{\mathrm{a}}$ & Species & $\begin{array}{l}\text { No. of analyzed } \\
\text { isolates }^{b}\end{array}$ & $\begin{array}{c}\text { Approximate } \\
\text { fragment length }\end{array}$ & $\begin{array}{l}\text { Banding pattern, } \\
\text { primary digest }^{c}\end{array}$ & $\begin{array}{l}\text { Secondary } \\
\text { enzyme }\end{array}$ & $\begin{array}{l}\text { Banding pattern, } \\
\text { secondary digest }^{d}\end{array}$ \\
\hline \multirow[t]{2}{*}{1} & Fusarium redolens & $9(2)$ & 730 & $290,260,150,30$ & \multirow[t]{2}{*}{$B s r \mathrm{BI}$} & $400,300,30$ \\
\hline & $F$. hostae $^{\mathrm{e}}$ & $1(1)$ & 730 & $290,260,150,30$ & & 400,330 \\
\hline \multirow[t]{4}{*}{2} & $F$. proliferatum $^{\mathrm{f}}$ & $2(1)$ & 710 & $320,260,130$ & \multirow[t]{4}{*}{$A l u \mathrm{I}$} & $380,190,100,40$ \\
\hline & F. subglutinans ${ }^{\mathrm{e}}$ & $1(1)$ & 710 & $320,260,130$ & & $300,200,100,70,40$ \\
\hline & F. verticillioides ${ }^{\mathrm{e}}$ & $1(1)$ & 710 & $320,260,130$ & & $330,190,100,50,40$ \\
\hline & F. oxysporum ${ }^{\mathrm{f}}$ & $22(8)$ & 710 & 710 or 450,260 or $320,260,130$ & & $380,190,100,40$ or $480,190,40$ \\
\hline \multirow[t]{3}{*}{3} & F. torulosum ${ }^{\mathrm{e}}$ & $1(1)$ & 710 & $290,250,170$ & \multirow[t]{3}{*}{ XhoI } & $340,310,60$ \\
\hline & F. avenaceum & $3(1)$ & 710 & $290,250,170$ & & 370,340 \\
\hline & F. tricinctum & $5(1)$ & 710 & $290,250,170$ & & 400,310 \\
\hline 4 & F. sporotrichioides ${ }^{\mathrm{e}}$ & $1(1)$ & 700 & $280,240,180$ & MaeII & $390,270,40$ \\
\hline \multirow[t]{3}{*}{5} & F. cerealis & $4(1)$ & 700 & $280,240,120,60$ & \multirow[t]{3}{*}{$B s p \mathrm{HI}$} & 620,80 \\
\hline & F. culmorum & $11(1)$ & 700 & $280,240,120,60$ & & 700 \\
\hline & F. graminearum $^{\mathrm{g}}$ & $5(1)$ & 710 & $410,240,60$ & & \\
\hline 6 & $F$. poae $^{\mathrm{e}, \mathrm{g}}$ & $1(1)$ & 700 & $300,240,160$ & & \\
\hline \multirow[t]{2}{*}{7} & F. sambucinum $\mathrm{e}$ & $1(1)$ & 700 & $280,240,180$ & \multirow[t]{2}{*}{ MaeII } & $370,280,30,20$ \\
\hline & F. venenatum & $4(1)$ & 700 & $280,240,180$ & & $380,270,30,20$ \\
\hline 8 & F. equiseti & $16(2)$ & 710 & 710 or 430,280 & \multirow[t]{2}{*}{$A l u \mathrm{I}$} & $480,190,40$ \\
\hline 9 & F. solani ${ }^{\mathrm{g}}$ & $8(5)$ & 730 & $290,170,150,90,30$ & & \\
\hline
\end{tabular}

a Main branch in Figure 1A.

b Numbers in parentheses indicate number of database sequences of the total amount of analyzed isolates.

c Banding patterns of Bst UI primary and secondary digests. Fragment sizes were rounded to the nearest $10 \mathrm{bp}$.

d Secondary restriction enzyme required for differentiation.

e Isolates were only subjected to translation elongation factor- $1 \alpha$ in silico analysis by database sequences.

f No further differentiation between $F$. proliferatum and $F$. oxysporum was achieved by second digest.

$\mathrm{g}$ Isolates could be differentiated from all other analyzed species using just the BstUI digest. 
and 3). The specific combination of two subsequent restriction digests resulted in all but two cases in characteristic band patterns differentiating the investigated Fusarium spp. Difficulties in a clear discrimination of the restriction pattern of Bst UI- and AluIdigested TEF-1 $\alpha$ PCR products from $F$. oxysporum and $F$. equiseti isolates were due to the very slight differences in the size of the restriction fragments in Bst $\mathrm{UI}$ digests and overlapping haplotype formation in AluI digests (Fig. 3). However, we were unable to obtain a better resolution by using an additional third restriction digest. Similarly, no restriction enzyme combination (in silico simulations applied 10 different enzymes) was able to differentiate TEF- $1 \alpha$ sequences from $F$. oxysporum and $F$. proliferatum. Although the isolates of $F$. oxysporum and $F$. proliferatum possessed $7 \%$ nucleotide sequence divergence in the analyzed TEF-1 $\alpha$ fragment region, it was not sufficient for species-specific discrimination, contrary to the possibility of differentiating 4, 4.6, and $2.3 \%$ sequence divergence between $F$. sambucinum $/ F$. venenatum, $F$. torulosum/F. avenaceum $/ F$. tricinctum, and $F$. redolens/ $F$. hostae, respectively. However, in addition to the use of reference isolates (Table 2), a detailed validation of the determined PCR-RFLP patterns of the different Fusarium spp. included additional 400 sugar-beet-derived Fusarium isolates. In almost every case, the PCR-RFLP-based result was in accordance with the morphological identification (data not shown).

\section{DISCUSSION}

In this study, molecular-based identification and differentiation of 65 isolates belonging to 11 Fusarium spp. isolated from sugar beet and additional 7 closely related species represented by TEF$1 \alpha$ nucleotide sequence database entries and culture collection reference isolates were conducted. In addition to the identification based on morphological data, for the first time we were able to provide evidence for the presence of these species in sugar beet using DNA-based identification methods.

The Fusarium spectrum isolated from sugar beet plantlets or freshly harvested beet worldwide consisted of 11 different species. This demonstrates that, in addition to F. oxysporum f. sp. betae and $F$. graminearum as reported previously (see introduction), sugar beet is already infested at harvest by many other Fusarium spp. The different Fusarium spp. partly coincided with the spectrum of species isolated from stored beet by Bosch and Mirocha (7), thereby implicating sugar beet as a host for $\mathrm{Fu}$ sarium spp. infections already in vegetative development. Further studies will be necessary to prove the ability of these pathogenic species and the environmental conditions required to actively

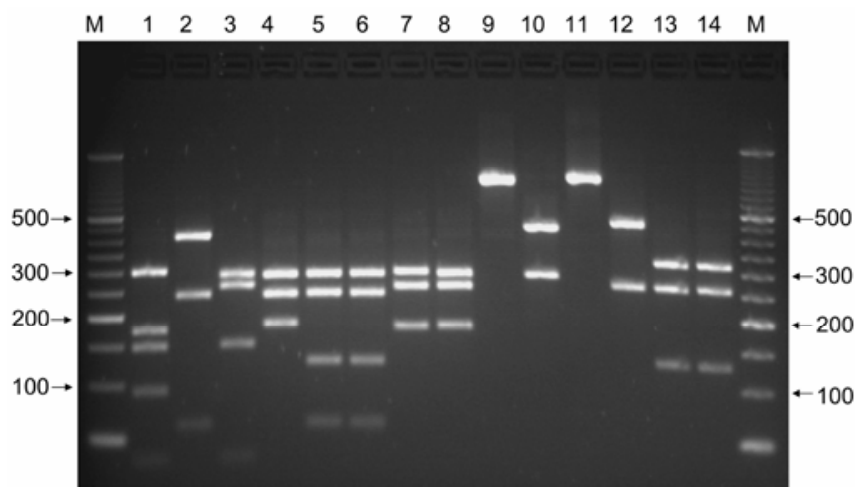

Fig. 2. Different restriction patterns of polymerase chain reaction-amplified translation elongation factor- $1 \alpha$ gene fragments of 11 Fusarium spp. obtained from sugar beet following digestion with Bst UI and analyzed in 3\% agarose gel. Lane M, 50-kb DNA ladder; lane 1, Fusarium solani; lane 2, F. graminearum; lane $3, F$. redolens; lane $4, F$. venenatum; lane $5, F$. culmorum; lane 6, F. cerealis; lane 7, F. avenaceum; lane 8, F. tricinctum; lanes 9 and 10, F. equiseti; lanes 11 to $13, F$. oxysporum; lane $14, F$. proliferatum. infect and colonize sugar beet and separate them from the saprophytes. Subsequent investigations also have to determine whether mycotoxins are produced in beet tissue by the different species because cross pathogenicity and mycotoxin production of sugar-beet-derived Fusarium isolates was already proven (11-13).

Considering the time-consuming and complex morphologybased identification of Fusarium spp., the need for a rapid and reliable identification assay for simultaneous determination covering a broad and diverse range of Fusarium spp. was evident. Compared with the use of species-specific PCR (see introduction), where one reaction for each species plus appropriate controls had to be carried out, the time expense for cloning and sequencing of the TEF-1 $\alpha$ gene fragment was comparable or even lower. Especially in cases where, as in the study presented here, the interest is focused on a broad and even unknown species spectrum, the sequencing of conserved housekeeping genes such as TEF- $1 \alpha$ allows a reliable identification within a similar time period $(18,28,44,49)$. Fungal isolation from the host was required to produce a pure culture as opposed to a direct molecular detection from host tissue extracted DNA to eliminate complications from mixed infections. This limits the possible application for Fusarium spp. in planta diagnosis but, on the other hand, eliminated difficulties in molecular detection due to sugar-beetderived inhibitory compounds (e.g., large amounts of polysaccharides in nucleic acid extracts). However, the isolation of Fusarium spp. from plant tissue proved to be very effective regarding the ease with which growth on solid media took place without any competition of bacterial growth. This offers the advantage of discriminating and subsequently identifying a large number of different Fusarium spp., starting from a single PCR product followed by sequencing of parallel obtained clones. As was shown by the partial TEF- $1 \alpha$ gene analysis conducted for the 65 isolates of this study, the sequence divergence was large enough to discriminate between that broad range of morphologically and even phylogenetically closely related Fusarium spp. The clustering of the dendrogram was supported by the supplemented database sequences of all species in this study, as well as $F$. verticillioides, $F$. subglutinans, $F$. sporotrichioides, $F$. poae, $F$. torulosum, F. sambucinum, and $F$. hostae. The pattern of TEF-1 $\alpha-$ based grouping of different species to well-supported clusters corresponded to close species relationships as described previously in a study on phylotoxigenic relationship (29). A phylogenetically related similarity of $F$. tricinctum and $F$. avenaceum was supported by ITS, IGS, mtSSU, and $\beta$-tubulin sequence analysis (62). In addition to these reports, the species description of $F$. hostae (19) supported the formation of $F$. hostae and $F$. redolens as a closely related clade, with clear distinction to the species complexes of Gibberella fujikuroi, $F$. solani, and $F$.

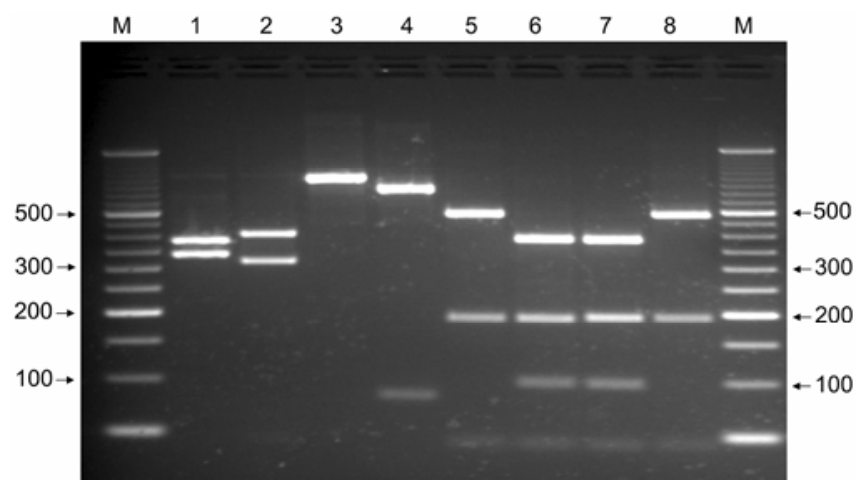

Fig. 3. Restriction patterns of differentially digested polymerase chain reaction-amplified translation elongation factor- $1 \alpha$ gene fragments analyzed in 3\% agarose gel. Lane M, 50-kb DNA ladder; lane 1, Fusarium avenaceum (XhoI); lane 2, F. tricinctum (XhoI); lane 3, F. culmorum (BspHI); lane 4, F. cerealis $(B s p \mathrm{HI})$; lanes 5 and $6, F$. oxysporum $(A l u \mathrm{I})$; lane $7, F$. proliferatum $($ AluI); lane 8, F. equiseti $(A l u \mathrm{I})$. 
oxysporum by molecular analyses of TEF- $1 \alpha$ and $\beta$-tubulin. The reliability and stability of our sequence analysis were supported by additional validation analyses. First, we added Fusarium database sequences to the analyzed Fusarium spp., as well as phylogenetically related species such as $F$. hostae, F. sambucinum, and $F$. torulosum or species such as $F$. sporotrichioides and $F$. subglutinans previously isolated from sugar beet. The additional analysis of sequences represented in the FUSARIUM-ID database for all the species isolated from sugar beet proved the reliability and indicated its potential use as an identification assay or diagnostic tool in other crops. The implementation of Fusarium reference isolates originating from different hosts (Table 2) already supports this application. However, a further validation of only in-silico-represented species would be desirable and would support differentiation results (e.g., for $F$. redolens and $F$. hostae in regard to discrimination difficulties using ITS-RFLP (5). Furthermore, it could also be used to confirm the putative identity of novel Fusarium spp. from sugar beet such as that recently reported by Rivera et al. (53).

The excellent TEF- $1 \alpha$-based differentiation of the analyzed Fusarium spp. prompted us to develop a PCR-RFLP assay as an advanced, technically simpler, and reliable tool for the speciesspecific determination and discrimination of Fusarium isolates. Interestingly, species-specific haplotypes were achieved for $F$. graminearum and $F$. solani, despite both species having been described as species complexes $(45,48)$. Although the F. graminearum-related Bst UI restriction pattern of TEF- $1 \alpha$ was consistent over the described seven phylogenetical lineages (50) of $F$. graminearum (with the exception of lineage 5) (data not shown), the $F$. solani-related BstUI restriction pattern was only valid for the cluster of sugar-beet-derived and most related sequences. The supplement of TEF-1 $\alpha$ sequences as representatives for the three $F$. solani clades (45) enabled no assignment of sugar-beet-derived $F$. solani isolates to these clades due to clear separation as distinct branches. Regarding the small number of investigated isolates in this study and the observation of $\approx 50$ species within the $F$. solani species complex (44), it is only possible to conclude that the chosen restriction enzyme $B s t \mathrm{UI}$ was suitable for the differentiation of $F$. solani isolates of this study from all other analyzed Fusarium spp. Investigations based on conserved 28S rDNA (21) and PCR-RFLP analysis of the more variable ITS region $(15,55)$ revealed $F$. solani as a polymorphic species; therefore, further detailed investigations are needed to determine the intraspecific differentiation of $F$. solani as well as the relation to pathogenicity for the isolates in this study.

The formation of three PCR-RFLP haplotypes in the species $F$. oxysporum indicated a high degree of intraspecific variability, possibly caused by the formation of a species complex (4). Representatives of all three $F$. oxysporum clades (49) were included and revealed a distribution of sugar-beet-derived $F$. oxysporum isolates over all three clades. Any further conclusions regarding a relation of the sugar-beet-derived $F$. oxysporum isolates to sugar-beetpathogenic $F$. oxysporum f. sp. betae were not possible, because no TEF- $1 \alpha$ sequences for $F$. oxysporum $\mathrm{f}$. sp. betae isolates were available. As detected for TEF-1 $\alpha$ in our study, Llorrens et al. (33) obtained intraspecific variability in IGS analysis and suggested the feasibility of converting this into differentiations at an intraspecific level. The potential to relate traits like pathogenicity of the isolates to the TEF-1 $\alpha$ haplotypes, as shown for bananaderived isolates of $F$. oxysporum (39), requires further investigations applying pathogenicity tests on sugar beet.

As outlined by Geiser (17), intron-rich portions of coding sequences are ideal markers for fungal phylogenetics. The TEF$1 \alpha$ gene proved to be a suitable genetic region for the differentiation of Fusarium spp. due to sufficient sequence variability in the intron sequences of the analyzed partial gene fragment (49). All restriction recognition sites chosen for differential digest were located in the intron sequences of the TEF-1 $\alpha$ gene. Available
PCR-RFLP assays based on ribosomal DNA sequences $(15,33,34)$ clustered analyzed species according to the haplotype formation by using four to six different restriction digests to reveal speciesspecific resolution of Fusarium spp. Compared with these approaches, the TEF- $1 \alpha$-based PCR-RFLP assay of our study required only two different digests whereby the restriction enzyme used for the second digest specifically depended on the restriction pattern of the Bst UI digest.

In conclusion, the isolation of 11 different Fusarium spp. from sugar beet enabled us to develop a DNA-based identification tool discriminating these species as well as related ones. The results revealed the suitability of this method for a fast and reliable identification of Fusarium spp. using two different restriction digests of one single PCR product. Further analyses are required to confirm its reliability in crops grown in rotation with sugar beet, especially cereals and maize. At least, the dataset extension with reference isolates derived from a diverse set of hosts (Table 2) strongly support those applications.

\section{ACKNOWLEDGMENTS}

We thank L. Hanson and R. Pilot for critical reading of the manuscript.

\section{LITERATURE CITED}

1. Agataev, M., and Ilyaletdinov, S. 1976. Rot of sugar beet root crops. Zashch. Rast. (Moscow) 8:16-17. (In Russian with English abstract)

2. Altschul, S. F., Madden, T. L., Schaffer, A. A., Zhang, Z. H., Zhang, Z., Miller, W. W., and Lippman, D. J. 1997. Gapped BLAST and PSIBLAST: A new generation of protein data-base search programs. Nucleic Acids Res 25:3389-3402.

3. Appel, D. J., and Gordon, T. R. 1996. Local and regional variation in populations of Fusarium oxysporum based on RFLP analysis of the intergenic spacer region of the ribosomal DNA. Mol. Plant-Microbe Interact. 9:125-138.

4. Baayen, R. P., O’Donnell, K., Bonants, P. J. M., Cigelnik, E., Kroon, L. P. N. M., Roebroeck, E. J. A., and Waalwijk, C. 2000. Gene genealogies and AFLP analyses in the Fusarium oxysporum complex identify monophyletic and nonmonophyletic formae specieales causing wilt and rot disease. Phytopathology 90:891-900.

5. Baayen, R. P., O'Donnell, K., Breeuwsma, S., Geiger, D. M., and Waalwijk, C. 2001. Molecular relationships of fungi within the Fusarium redolens-F. hostae clade. Phytopathology 91:1037-1044.

6. Bogale, M., Wingfield, B. D., Wingfield, M. J., and Steenkamp, E. T. 2007. Species-specific primers for Fusarium redolens and a PCR-RFLP technique to distinguish among three clades of Fusarium oxysporum. FEMS Microbiol. Lett. 271:27-32.

7. Bosch, U., and Mirocha, C. J. 1992. Toxin production of Fusarium species from sugar beets and natural occurrence of zearalenone in beets and beet fibers. Appl. Environ. Microbiol. 58:3233-3239.

8. Böttcher, I., and Behr, L. 1980. Fusarium ssp. als Erreger des Wurzelbrandes und einer Seitenwurzelkrankheit der Zuckerrübe. Arch. Phytopathol. Pflanzenschutz 16:380-396.

9. Bugbee, W. M. 1982. Storage rot of sugar beet. Plant Dis. 66:871-873.

10. Burgess, L. W. 1981. General ecology of Fusaria. Pages 225-235 in: Fusarium, Diseases, Biology, and Taxonomy. P. E. Nelson, T. A. Toussoun, and R. J. Cook, eds. Pennsylvania State University Press, University Park.

11. Burlakoti, R. R., Ali, S., Secor, G. A., Neate, S. M., McMullen, M. P., and Adhikari, T. B. 2008. Comparative mycotoxin profiles of Gibberella zeae populations from barley, wheat, potatoes, and sugar beets. Appl. Environ. Microbiol. 74:6513-6520.

12. Burlakoti, R. R., Ali, S., Secor, G. A., Neate, S. M., McMullen, M. P., and Adhikari, T. B. 2008. Genetic relationships among populations of Gibberella zeae from barley, wheat, potato and sugar beet in the upper Midwest of the United States. Phytopathology 98:969-976.

13. Burlakoti, R. R., Estrada, R., Jr., Rivera, V. V., Boddeda, A., Secor, G. A., and Adhikari, T. B. 2007. Real-time PCR quantification and mycotoxin production of Fusarium graminearum in wheat inoculated with isolates collected from potato, sugar beet and wheat. Phytopathology 97:835-841.

14. Duggal, A., Dumas, M. T., Jeng, R. S., and Hubbes, M. 1997. Ribosomal variation in six species of Fusarium. Mycopathologia 140:35-49.

15. Edel, V., Steinberg, C., Gautheron, N., and Alabouvette, C. 1996. Evaluation of restriction analysis of polymerase chain reaction (PCR)amplified ribosomal DNA for the identification of Fusarium species. Mycol. Res. 101:179-187. 
16. Estrada, R., Jr., Rivera, V. V., and Secor, G. A. 2007. Pathogenicity of Fusarium graminearum to potato, sugar beet, and wheat. (Abstr.) Phytopathology 97:S160.

17. Geiser, D. M. 2003. Practical molecular taxonomy of fungi. In: Advances in Fungal Biotechnology for Industry, Medicine and Agriculture. L. Lange, and J. Tkacz, eds. Kluwer Academic Publishers, Dordrecht, The Netherlands.

18. Geiser, D. M., del Mar Jiménez-Gasco, M., Kang, S., Makalowska, I., Veeraraghavan, N., Ward, T. J., Zhang, N., Kuldau, G. A., and O'Donnell, K. 2004. Fusarium-ID v. 1.0: a DNA sequence database for identifying Fusarium. Eur. J. Plant Pathol. 110:473-479.

19. Geiser, D. M., Juba, J. H., Wang, B., and Jeffers, S. N. 2001. Fusarium hostae sp. nov., a relative of $F$. redolens with a Gibberella teleomorph. Mycologia 93:670-678.

20. Gross, D. C., and Leach, L. D. 1973. Stalk blight of sugar beet crops caused by Fusarium oxysporum f. sp. betae. (Abstr.) Phytopathology 63:1216.

21. Guadet, J., Julien, J., Lafay, J. F., and Brygoo, Y. 1989. Phylogeny of some Fusarium species, as determined by large-subunit rRNA sequence comparison. Mol. Biol. Evol. 6:227-242.

22. Hanson, L. E. 2006. Fusarium yellowing of sugar beet caused by Fusarium graminearum from Minnesota and Wyoming. Plant Dis. 90:686.

23. Harveson, R. M., and Rush, C. M. 1998. Characterization of Fusarium root rot isolates from sugar beet by growth and virulence at different temperatures and irrigation regimes. Plant Dis. 82:1039-1042.

24. Hinojo, M. J., Llorens, A., Mateo, R., Patino, B., González-Jaén, M. T., and Jiménez, M. 2004. Utility of the polymerase chain reaction-restriction fragment length polymorphisms of the intergenic spacer region of the rDNA for characterizing Gibberella fujikuroi isolates. Syst. Appl. Microbiol. 27:681-688.

25. Jurado, M., Vásquez, C., Marin, S., Sanchis, V., and González-Jaén, M. T. 2006. PCR-based strategy to detect contamination with mycotoxigenic Fusarium species in maize. Syst. Appl. Microbiol. 29:681-689.

26. Jurado, M., Vásquez, C., Patino, B., and González-Jaén, M. T. 2005. PCR detection assays for the trichothecene-producing species Fusarium graminearum, Fusarium culmorum, Fusarium poae, Fusarium equiseti and Fusarium sporotrichioides. Syst. Appl. Microbiol. 28:562-568.

27. Kockova-Kratochvilova, A., Kutkova, M., and Petrova, M. 1958. The genus Fusarium, which caused heart rot in sugar beet in 1956 in Slovakia. Czech. Mycol. 12:83-94.

28. Knutsen, A. K., Torp, M., and Holst-Jensen, A. 2004. Phylogenetic analyses of the Fusarium poae, Fusarium sporotrichioides and Fusarium langsethiae species complex based on partial sequences of the translation elongation factor-1 alpha gene. Int. J. Food Microbiol. 95:287-295.

29. Kristensen, R., Torp, M., Kosiak, B., and Holst-Jensen, A. 2005. Phylogeny and toxigenic potential is correlated in Fusarium species as revealed by partial translation elongation factor 1 alpha gene sequences. Mycol. Res. 109:173-186.

30. Kulik, T., Fordonski, G., Pszczolkowska, A., Plodzien, K., and Lapinski, M. 2004. Development of PCR assay based on ITS2 rDNA polymorphism for the detection and differentiation of Fusarium sporotrichioides. FEMS Microbiol. Lett. 239:181-186.

31. Leslie, J. F., and Summerell, B. A. 2006. The Fusarium Laboratory Manual. Blackwell Publishing, Iowa.

32. Leslie, J. F., Zeller, K. A., and Summerell, B. A. 2001. Icebergs and species in populations of Fusarium. Physiol. Mol. Plant Pathol. 59:107-117.

33. Llorens, A., Hinojo, M. J., Mateo, R., Gonzalez-Jaen, M. T., ValleAlgarra, F. M., Logrieco, A., and Jimenez, M. 2005. Characterization of Fusarium spp. isolates by PCR-RFLP analysis of the intergenic spacer of the IGS region of the rRNA gene (rDNA). Int. J. Food Microbiol. 106:297-306

34. Llorens, A., Hinojo, M. J., Mateo, R., Medina, A., Valle-Algarra, F. M., Gonzalez-Jaen, M. T., and Jimenez, M. 2006. Variability and characterization of mycotoxin-producing Fusarium ssp. isolates by PCRRFLP analysis of the IGS-rDNA region. Antonie Leeuwenhoek 89:465478.

35. MacDonald, J. D., Leach, L. D., and McFarlane, J. S. 1976. Susceptibility of sugar beet lines to the stalk blight pathogen Fusarium oxysporum f. sp. betae. Plant Dis. Rep. 60:192-196.

36. Martyn, R. D., Rush, C. M., Biles, C. L., and Baker, E. H. 1989. Etiology of a root rot disease of sugar beet in Texas. Plant Dis. 73:879-884.

37. Mishra, P. K., Fox, R. T. V., and Culham, A. 2002. Restriction analysis of PCR amplified nrDNA regions revealed intraspecific variation within populations of Fusarium culmorum. FEMS Microbiol. Lett. 215:291-296.

38. Mule, G., Logrieco, A., Stea, G., and Bottalico, A. 1997. Clustering of trichothecene-producing Fusarium strains determined from $28 \mathrm{~S}$ ribosomal DNA sequences. Appl. Environ. Microbiol. 63:1843-1846.
39. Nel, B., Steinberg, C., Labuschagne, N., and Viljoen, A. 2006. Isolation and characterization of nonpathogenic Fusarium oxysporum isolates from the rhizosphere of healthy banana plants. Plant Pathol. 55:207-216.

40. Nelson, P. E., Toussoun, T. A., and Marasas, W. F. O. 1983. Fusarium Species: An Illustrated Manual for Identification. Pennsylvania State University, University Park.

41. Nirenberg, H. I. 1976. Untersuchungen über die morphologische und biologische Differenzierung in der Fusarium -Sektion Liseola. Mitt. Biol. Bundesanst. Land Forstwirtsch. Berlin-Dahlem 169:1-117.

42. Nirenberg, H. I. 1995. Morphological differentiation of Fusarium sambucinum Fuckel sensu stricto, F. torulosum (Berk. \& Curt.) Nirenberg comb. nov. and $F$. venenatum Nirenberg sp. nov. Mycopathologia 129:131-141.

43. O’Donnell, K. 1992. Ribosomal DNA internal transcribed spacers are highly divergent in the pythopathogenic ascomycete $F$. sambucinum (Gibberella pulicaris). Curr. Genet. 22:213-220.

44. O'Donnell, K. 1996. Progress towards a phylogenetic classification of Fusarium. Sydowia 48:57-70.

45. O'Donnell, K. 2000. Molecular phylogeny of the Nectria haematococcaFusarium solani species complex. Mycologia 92:919-938.

46. O’Donnell, K., Cigelnik, E., and Casper, H. H. 1998. Molecular phylogenetic, morphological, and mycotoxin data support reidentification of the Quorn mycoprotein fungus as Fusarium venenatum. Fungal Genet. Biol. 23:57-67.

47. O’Donnell, K., Cigelnik, E., and Nirenberg, H. I. 1998. Molecular systematics and phylogeography of the Gibberella fujikuroi species complex. Mycologia 90:465-493.

48. O'Donnell, K., and Gray, L. E. 1995. Phylogenetic relationships of the soybean sudden death syndrome pathogen Fusarium solani f. sp. phaseoli from rDNA sequence data and PCR primers for its identification. Mol. Plant-Microbe Interact. 5:709-716.

49. O’Donnell, K., Kistler, H. C., Cigelnik, E., and Ploetz, R. C. 1998c. Multiple evolutionary origins of the fungus causing Panama disease of banana: concordant evidence from nuclear and mitochondrial gene genealogies. Proc. Natl. Acad. Sci. USA 95:2044-2049.

50. O'Donnell, K., Kistler, H. C., Tacke, B. K., and Casper, H. H. 2000. Gene genealogies reveal global phylogeographic structure and reproductive isolation among lineages of Fusarium graminearum, the fungus causing wheat scab. Proc. Natl. Acad. Sci. USA 97:7905-7910.

51. Page, R. D. 1996. TreeView: an application to display phylogenetic trees on personal computers. Comput. Appl. Biosci. 12:357-358.

52. Quarta, A., Mita, G., Haidukowski, M., Logrieco, A., Mule, M., and Visconti, A. 2006. Multiplex PCR assay for the identification of nivalenol, 3- and 15-acetyl- deoxynivalenol chemotypes in Fusarium. FEMS Microbiol. Lett. 259:7-13.

53. Rivera, V., Rengifo, J., Khan, M., Geiser, D. M., Mansfield, M., and Secor, G. 2008. First report of a novel Fusarium species causing yellowing decline of sugar beet in Minnesota. Plant Dis. 92:1589

54. Rush, C. M., and Martyn, R. D. 1991. Variation in sugar beet susceptibility to isolates of Fusarium oxysporum f. sp. betae from Texas and Oregon. (Abstr.) Phytopathology 81:1200.

55. Suga, H., Hasegawa, T., Mitsui, H., Kageyama, K., and Hyakumachi, M. 2000. Phylogenetic analysis of the phytopathogenic fungus Fusarium solani based on the rDNA-ITS region. Mycol. Res. 104:1175-1183.

56. Taylor, J. W., Jacobson, D. J., Kroken, S., Kasuga, T., Geiser, D. M., Hibbett, D. S., and Fisher, M. C. 2000. Phylogenetic species recognition and species concepts in fungi. Fungal Genet. Biol. 31:21-32.

57. Thompson, J. D., Gibson, T. J., Plewniak, F., Jeanmougin, F., and Higgins, D. G. 1997. The CLUSTAL_X windows interface: flexible strategies for multiple sequence alignment aided by quality analysis tools. Nucleic Acids Res. 25:4876-4882.

58. Thrane, U. 1989. Fusarium species and their specific profiles of secondary metabolites. Pages 199-225 in: Fusarium: Mycotoxins, Taxonomy and Pathogenicity. J. Chelkowski, ed. Elsevier, Amsterdam.

59. Turner, A. S., Lees, A. K., Rezanoor, H. N., and Nicholson, P. 1998. Refinement of PCR-detection of Fusarium avenaceum and evidence from DNA marker studies for phenetic relatedness to Fusarium tricinctum. Plant Pathol. 47:278-288.

60. Ward, T. J., Bielawski, J. P., Kistler, H. C., Sullivan, E., and O'Donnell, K. 2002. Ancestral polymorphism and adaptive evolution in the trichothecene mycotoxin gene cluster of phytopathogenic Fusarium. Proc. Natl. Acad. Sci. USA 99:9278-9283.

61. Whitney, E. D., and Duffus, J. E., eds. 1986. Compendium of Beet Diseases and Insects. American Phytopathological Society, St. Paul, MN.

62. Yli-Mattila, T., Paavanen-Huhtala, S., Bulat, S. A., Alekhina, I. A., and Nirenberg, H. I. 2002. Molecular, morphological and phylogenetic analysis of the Fusarium avencaeum/F. arthrosporioides $/ F$. tricinctum species complex — a polyphasic approach. Mycol. Res. 106:655-669. 